\title{
BIBLIOGRAFÍA SOBRE TEATRO Y NUEVAS TECNOLOGÍAS: FORMAS DE REPRESENTACIÓN EN LA ERA DIGITAL
}

\section{Alberto Hermida Congosto \\ Universidad de Sevilla}

- ABIRACHED, R. (1994): La crisis del personaje en el teatro moderno, Madrid, Publicaciones de la Asociación de Directores de Escena.

• ABUÍN GONZÁLEZ. A. (2008): “Teatro y nuevas tecnologías. Conceptos básicos”, en Revista Signa, 17, 29-56.

- ABUÍN, A. (2006): Escenarios del caos. Entre la hipertextualidad y la performance en la era electrónica, Valencia, Tirant lo Blanch.

- AUSLANDER, Ph. (1999): Liveness. Performance in a Mediatized Culture, Londres, Routledge.

- BARROSO VILLAR, Ma . E. (ed.) (2005): Comunicación, universo artístico y nuevas tecnologías, Sevilla, Alfar.

- BAUGH, Ch. (2005): Theatre, Performance and Technology. The Development of Scenography in the Twentieth Century, Nueva York, Palgrave MacMillan.

- BIRRINGER, J. (1998): Media and Performance: Along The Border, Baltimore, Maryland, The John Hopkins University Press.

- (2006): “Interacting”, en Contemporary Theatre Review 16.4, 389-405.

• BOLTER, J. y GRUSIN, R. (1999): Remediation, Cambridge, Massachussets, MIT Press. 
- CARROLL, J. (1996): "Drama and Technology: Realism and Emotional Literacy”, en NADIE Journal (NJ), 20 (2), 7-17.

- (2002). "Digital Drama: A Snapshot of Evolving Forms” en Melbourne Studies in Education, 43(2), 130-141.

- CARVER, G. y BEARDON, C. (eds.) (2004): New Visions in Performance. The Impact of New Technologies, Lisse, Swets \& Zeitlinger.

- CAUSEY. M. (1999): “Postorganic Performance: The Appearance of Theater in Virtual Spaces”, en Cyberspace Textuality: Computer Technology and Literary Theory, ed. Marie-Laure Ryan, Bloomington \& Indiana, Indiana University Press.

- (2006): Theatre and Performance in Digital Culture. From Simulation to Enbeddedness, Londres, Routledge.

- CORNAGO, O. (2004): "El cuerpo invisible. Teatro y tecnologías de la imagen”, en Árbor 699-700, 595-610.

- COTAIMICH, V. (2004): "El impacto de las nuevas tecnologías en la puesta en escena. La estética dialógica como desafío estético, poético y político”. Publicación en CD: VI Jornadas de Arte y Medios Digitales. Primer Simposio: Prácticas de Comunicación Emergente en la Cultura Digital, Córdoba, Facultad de Filosofía y Humanidades, Universidad Nacional de Córdoba.

- DARLEY, A. (2002): Cultura visual digital. Espectáculo y nuevos géneros en los medios de comunicación, Barcelona, Piadós.

- DE MARINIS, M. (1997): Comprender el teatro: Lineamientos de una nueva teatrología, Buenos Aires, Galerna.

- DIXON, S. (2002): "Internet Theatre, Posthuman Bodies and the Interctive Void”, en E-pai: Performance Arts International on-line Journal, número único anual. En línea en http://www.mdx.ac.uk/www/epai/presencesite/html/dixontol01.html (2/IV/2008).

- (2007). Digital Performance. A History of New Media in Theater, Dance, Performance Art and Installation. Cambridge, Mass.: The MIT Press. 
• ECHEVERRÍA, J. (2003): “Cuerpo electrónico e identidad”, en Hernández D. (ed.): Arte, cuerpo, tecnología. Salamanca, Salamanca, Publicaciones de la Universidad de Salamanca, 13-29.

• ETCHELLS, T. (1999): Certain Fragments: Contemporary Performance and Forced Entertainment, Londres, Routledge.

- FLINTOFF, K. (2002a). "Drama and Technology. The Pursuit of Uncertain Benefits” (Keynote Address), en Drama Queensland says... The Journal of the Queensland Association for Drama in Education, 25 \#2 (Left Blank Intentionally).

- (2002b): "Drama in Cyberspace”, en School Matters (The Education Department of Western Australia) \#10.

- (2003): "Stepping into the Virtual. Is Virtuality a Contemporary Alternative to Drama?” en Heikkinen, H. (ed.): Special Interest Fields of Drama, Theatre and Education: The IDEA-dialogues, 134-141. Jyväskylä, Finland: Jyväskylä University Press.

• GIANNACHI, G. (2005): Virtual Theatres. An Introduction, Londres, Routledge.

- GIANNETTI, Cl. (1995): “Metaformance. Proceso troposomático en la performance multimedia”, en Giannetti, Claudia (ed.): Media Culture, Barcelona, Asociación de Cultura Contemporánea L’Angelot.

• GRAU, O. (2003): Virtual Art: From Illusion to Inmersión, Cambridge, Mass.: The MIT Press.

- JENSEN, A. P. (2007): Theatre in a Media Culture. Production, Performace and Perception Since 1970, Jefferson, McFarland.

• JORDAN, N. (2002): "How New is New Media? The History of Multi-media Usage in Theatrical Productions”. Drama Australia Journal (NJ), 26(2), 73-82.

- KAYE, N. (1994): Posmodernism and Performance (New Directions in Theatre), Palgrave MacMillan.

- (2007): Multi-media: Video, Installations, Performance, Londres, Routledge. 
- KING, G. y KRZYWINSKA, T. (eds.) (2002): Screenplay: Cinema / Videogames / Interfaces, Wallflower Press.

- LAUREL, B. (1991): Computer as Theatre, Reading, Mass,: Addison-Wesley.

• LÓPEZ-VARELA AZCÁRATE, A. (2008): “El gusto del público: La magia digital”, en Revista Signa, 17, 57-84.

- MANOVICH, L. (2006): El Lenguaje de los nuevos medios de comunicación. La imagen en la era digital, Barcelona, Paidós, 2006.

• MARTÍNEZ THOMAS, M. y POUGET. M, (2008): “Drama: La utopía de la notación escénica”, en Revista Signa, 17, 131-150.

- MURRIA, J.H. (1999): Hamlet en la holocubierta. El futuro de la narrativa en el ciberespacio, Barcelona, Paidós.

- POYATOS, F. (1994): La comunicación no verbal, III. Nuevas perspectivas en novela y teatro y en su traducción, Madrid, Istmo.

- RIESER, M. y ZAPP, A. (eds.) (2002): New Screen Media: Cinema / Art / Narrative, BFI Publishing.

• ROMERA CASTILLO, J. (2008): "Hacia un estado de la cuestión sobre teatro y nuevas tecnologías en España”, en Revista Signa, 17, 17-28.

- (ed.) (2004): Teatro, prensa y nuevas tecnologías (1990-2003), Madrid, Visor Libros.

- (2006): Tendencias escénicas al inicio del Siglo XXI, Madrid, Visor Libros.

· SALTZ, David Z. (2001): “Live Media: Interactive Technology and Theatre”, en Theatre Topics - 11-2, 107-130.

• SOMERS, J. (1998). “Disney, Drama and Virtual Worlds”, en NADIE Journal (NJ), 22(2), 55-68.

- WARDEIP-FRUIN, N. y HARRIG, P. (2004): Firstperson. New Media as Story, Performance and Game, Cambridge, Mass.: MIT Press.

- WRIGHT, E. A. (1995): Para comprender el teatro actual, México, Fondo de Cultura Económica. 
- VV.AA. (1999). Theatre and Technology, en Theatre Jorunal 51, 4.

\section{BIBLIOGRAFÍA DESTACADA}

\section{- ABUÍn, A. (2006): Escenarios del caos. Entre la hipertextualidad y la performance en la era electrónica, Valencia, Tirant lo Blanch.}

Anxo Abuín analiza en este libro ámbitos como el cinematográfico, el literario o la performance y las nuevas tecnologías desde una perspectiva que centra la mirada en la impredecibilidad y las teorías del caos. Lo mutable y lo efímero se establecen como contexto idóneo para cualquier acto artístico, el cual se desarrolla en una "situación comunicativa in statu nascendi, palmariamente incompleta y fragmentaria”.

- CAUSEY. M. (2006): Theatre and Performance in Digital Culture. From Simulation to Enbeddedness, Londres, Routledge.

La obra muestra las repercusiones e influencia que las nuevas tecnologías, los medios actuales y ciertos fenómenos culturales contemporáneos (así como otros avances y acontecimientos destacados) han tenido sobre teatro y performance. En una sociedad cada vez más tecnificada y dependiente de la tecnología en avance constante y tras hechos tan determinantes como las guerras de Irak o el atentado del 11 de septiembre, Matthew Causey nos muestra fundamentalmente cómo el teatro 
evoluciona adaptándose a la cultura digital, que condiciona la esencia y la estética de cualquier modelo tradicional o preexistente.

- GIANNACHI, G. (2005): Virtual Theatres. An Introduction, Londres, Routledge.

Se trata de una interesante obra que gira en torno al teatro del siglo XXI y a la simulación a la que todo es susceptible. Con esta lectura de las nuevas formas de representación, condicionadas por la tecnología y el uso del ordenador en el ámbito artístico, Gabriella Giannachi revisa algunos conceptos como el espacio, el tiempo o la identidad; unas realidades que se ven fuertemente afectadas por la influencia de la virtualidad en la cultura, la vida y la estética de nuestros días.

- GRAU, O. (2003): Virtual Art: From Illusion to Inmersión, Cambridge, Mass.: The MIT Press.

Oliver Grau sumerge al lector en una asombrosa revisión del arte y lo visual a través del prisma de la realidad virtual. La ilusión, la presencia o los espacios envolventes cobran protagonismo en esta obra, en la que su autor hace un recorrido por las distintas formas que favorecen la inmersión del espectador: desde muy antiguas manifestaciones hasta las expresiones artísticas más actuales.

- RIESER, M. y ZAPP, A. (eds.) (2002): New Screen Media: Cinema / Art / Narrative, BFI Publishing.

En un contexto en el que la narrativa se fragmenta y las nuevas formas se centran en la inmersión y la interactividad como principios dominantes, se hace más que necesario el estudio de las distintas prácticas artísticas que se centran en el poder de las pantallas, la imagen en movimiento y la participación del espectador. De este modo y mediante una obra que combina los estudios de reconocidos teóricos, las visiones de artistas experimentales e interesantes trabajos editados en DVD, se 
exploran las distintas soluciones que afectan a la representación visual y la narración contemporáneas. 